\title{
CORRECTION
}

\section{Correction to: Heparin resistance in COVID-19 patients in the intensive care unit}

\author{
D. White ${ }^{1}$ - S. MacDonald ${ }^{1}$ - T. Bull ${ }^{1} \cdot$ M. Hayman $^{1}$ - D. de Monteverde-Robb ${ }^{2}$ - D. Sapsford ${ }^{2} \cdot$ A. Lavinio ${ }^{3} \cdot$ J. Varley $^{3}$. \\ A. Johnston ${ }^{3} \cdot$ M. Besser ${ }^{1} \cdot$ W. Thomas ${ }^{1}(\mathbb{C}$
}

Published online: 22 June 2020

(c) Springer Science+Business Media, LLC, part of Springer Nature 2020

\section{Correction to: Journal of Thrombosis and Thrombolysis https://doi.org/10.1007/s11239-020-02145-0}

In the original publication of this article, one of the coauthor name "D. de Monteverde-Robb" was inadvertently mentioned as "R. de Monteverde-Robb". The correct author name is "D. de Monteverde-Robb". This error has been corrected with this erratum.

Publisher's Note Springer Nature remains neutral with regard to jurisdictional claims in published maps and institutional affiliations.

The original article can be found online at https://doi.org/10.1007/ s11239-020-02145-0.

W. Thomas

william.thomas@addenbrookes.nhs.uk

1 Department of Haematology, Cambridge University Hospitals NHS Foundation Trust, Cambridge, UK

2 Pharmacy Department, Cambridge University Hospitals NHS Foundation Trust, Cambridge, UK

3 Department of Intensive Care Medicine, Cambridge University Hospitals NHS Foundation Trust, Cambridge, UK 